\title{
Cultura Kaingang: saberes e identidades direcionados aos desafios contemporâneos da preservação e da educação ambiental $^{1}$
}

\begin{abstract}
Resumo
O povo Kaingang organiza-se socialmente em dois segmentos ou dualidades, kamẽ e kanhru, cada qual com suas características e habilidades. Na natureza, tudo se relaciona com as marcas kamẽ e kanhru; há semelhanças nas pinturas corporais, nas peles dos animais, nas folhas e cascas de árvores. É algo que diz respeito à identidade: o kamẽ usa as pinturas compridas no corpo e também nos artesanatos; o kanhru utiliza traços circulares no corpo e também nos artesanatos e identifica os animais com suas marcas. Essa dualidade vincula-se à perpetuação de suas tradições. A vida dos Kaingang funciona com base na espiritualidade, que permeia aspectos culturais. $O$ abandono e a falta de valorização de saberes e práticas relacionados com a educação ambiental se concretizam pelas pressões da sociedade branca, pelo desejo de alguns indígenas de serem modernos e aceitos e pela ausência de trabalho de um educador ambiental. O presente artigo discute aspectos da cultura Kaingang, apresenta dados e reflexões sobre experiências vividas em terras indígenas no Rio Grande do Sul e destaca desafios para a preservação dos seus costumes e de seu ambiente circundante, consideradas preciosos pelos Kaingang.
\end{abstract}

Palavras-chave: Cultura. Identidade. Índios. Kaingang.

\author{
Darci Emiliano \\ Mestre em Educação Ambiental \\ pela Universidade Federal do Rio \\ Grande - FURG. \\ Doutorando em Educação \\ Ambiental na Universidade \\ Federal do Rio Grande - FURG. \\ Brasil \\ darci.emiliano@sertao.ifrs.edu.br
}

\section{Alfredo Guillermo Martin}

Doutor em Ciências da Educação pela Université Paris 8 -

Vincennes-Saint-Denis.

Professor da Universidade

Federal do Rio Grande - FURG.

Brasil

martingen@ibest.com.br

\section{Vilmar Alves Pereira}

Doutor em Educação pela

Universidade Federal do Rio

Grande do Sul - UFRGS.

Professor Universidade Federal

do Rio Grande - FURG.

Brasil

vilmar1972@gmail.com

\section{Para citar este artigo:}

EMILIANO, Darci; MARTIN, Alfredo Guillermo; PEREIRA, Vilmar Alves. Cultura Kaingang: saberes e identidades direcionados aos desafios contemporâneos da preservação e da educação ambiental. Revista PerCursos, Florianópolis, v. 19, n.41, p. 203- 233, set./dez. 2018.

\section{DOI: 10.5965/1984724619412018203}

http://dx.doi.org/10.5965/1984724619401018203

\footnotetext{
${ }^{1}$ O texto toma como base o primeiro capítulo da dissertação de mestrado Revitalização dos saberes $e$ práticas Kaingang sobre as plantas tradicionais como proposta de educação ambiental na Terra Indígena Ligeiro (EMILIANO, 2015).
} 


\title{
Kaingang Culture: Knowledge and Identity addressed to Contemporary Challenges of Environmental Preservation and Education.
}

\begin{abstract}
The Kaingang people organize themselves socially into two segments or dualities, kamẽ and kanhru, each with its characteristics and abilities. In nature everything is related to the kamẽ and kanhru marks, there are similarities in body paintings, animal skins, leaves and barks: the kamẽ, uses the long paintings in the body and also in the crafts; the kanhru uses circular traces in the body and also in the crafts and identify the animals with their marks. This duality is linked to the perpetuation of their traditions. The life of the Kaingang works on the basis of spirituality, which permeates cultural aspects. The abandonment and lack of appreciation of knowledge and practices related to environmental education are materialized by the pressures of white society, the desire of some Indians to be modern and accepted in white society and by the absence of work of an environmental educator. This article discusses aspects of the Kaingang culture, presents data and reflections about experiences lived in indigenous lands in Rio Grande do Sul and highlights challenges for the preservation of their customs and surrounding environment, considered precious by the Kaingang.
\end{abstract}

Keywords: Culture. Identity. Indians. Kaingang. 


\section{Elementos básicos da cultura Kaingang}

Em tempos imemoráveis, deu-se um dilúvio que cobriu a terra inteira, habitada de nossos antepassados. Somente o cume da serra Krinjinjimbé (Serra do Mar) sobressaía das águas diluviais. Os kaingang, kaiurukré e kamẽ nadavam na direção dela, cada um com um luminoso tição entre os dentes. Os kaiurukré e os kamẽ cansaram, afundaram-se e pereceram; suas almas foram habitar o interior da montanha. Os kaingang e uns poucos curutons atingiram com dificuldade o cume da serra, onde permaneceram uns no chão, outros nos ramos das árvores porque não acharam mais lugar. Lá passaram uns dias sem alimento e sem que as águas baixassem. Já esperavam a morte, quando ouviram o canto das saracuras que traziam cestinhos de terra, que deitavam nas águas. Assim, as águas foram recuando devagar. Os kaingang clamavam às saracuras que se apressassem. Estas redobraram suas vozes e pediram aos patos que as ajudassem. Em pouco tempo conseguiram formar uma planície espaçosa no monte, que dava bastante campo aos kaingang, com exceção daqueles que se refugiaram nas árvores. Estes foram transformados em macacos e os curutons em macacos urradores. Desaparecida a inundação, os kaingang estabeleceram-se nas proximidades da Serra do Mar. Os kaiurukré e os kamẽ, cujas almas moravam no interior da serra, começaram a abrir caminhos. Depois de muitos trabalhos e fadigas, uns puderam sair de um lado, os outros do outro. Na abertura de onde saíram os kaiurukrés, teve sua nascente um belo arroio e lá não havia pedras; daí veio que eles têm os pés pequenos. Pelo contrário o caminho dos kamẽ levava sobre terreno pedregoso, daí eles terem os pés compridos. Na noite em que tinham saído da abertura da serra, acenderam fogo e kaiurukré formou de cinzas e carvão tigres e Ihes disse: ide e devorai homens e animais! E os tigres se foram rugindo. Não tendo mais carvão para pintar, fez de cinza as antas e disse-lhes: ide e comei folhas e ramos! Kaiurukré estava outra vez a formar um animal; faltavam a este ainda os dentes, a língua e umas garras quando apontou o dia. Não tendo mais forças de dia, pôs-lhe uma vara na boca e disse-lhe: não tendo dentes, vive de formigas! Isto é a razão por que o tamanduá é um animal não acabado e imperfeito. Na noite seguinte continuou e formou outros animais, entre eles as abelhas boas. Kamẽ também fez animais, porém diversos, para combater aqueles. Assim ele fez os leões americanos, as cobras venenosas e as vespas. Acabado este trabalho, marcharam e foram se unir aos kaingang. [...] Depois de terem chegado a uma grande planície, reuniram-se e aconselharam-se como deviam casar os filhos. Casaram primeiro os kaiurukré com as filhas do kamẽ, e vice versa. Quando porém, restavam ainda muitos jovens, casaram-nos com as filhas dos kaingang. E daí veio que os kaiurukré, os kaingang e os kamẽ são parentes e amigos. ${ }^{2}$ (JAHN; TETTEMANZY; FREITAS, 2007)

\footnotetext{
${ }^{2}$ Narrado pelo Cacique Arakxô a Telêmaco Borba, em 1908.
} 
De acordo com Fakój Kaingang (2013), o povo Kaingang organiza-se socialmente em dois clãs segmentos ou dualidades que, ao contrário da lógica branca, não são opostos, mas sim complementares. Conta-se que, no princípio do mundo, os Kaingang surgiram do solo, por isso a cor da pele do corpo dos índios é semelhante à cor da terra. Formaram-se dois grupos, kamẽ e kanhru, cada qual com suas características e habilidades. Os Kamẽ são caracterizados pela força, por serem guerreiros, terem o corpo avantajado, pés e mãos grandes, unhas compridas, mas são vagarosos. Já os Kanhru têm o corpo franzino, as mãos e pés pequenos, unhas curtas, são ágeis no pensamento e na iniciativa, mas têm pouca persistência.

Ainda sobre esse aspecto, Rosa (2005) enfatiza que a dualidade não está presente só nas pessoas, mas nas plantas, nos animais, nos planetas, no sol e na lua, nos fenômenos meteorológicos que permeiam todas as redes. Na natureza tudo se relaciona com as marcas kamẽ e kanhru; sua presença está nas pinturas corporais, nas peles dos animais, nas folhas e cascas de árvores. O kamẽ usa as pinturas compridas no corpo e também nos artesanatos; o kanhru utiliza traços circulares no corpo e também nos artesanatos e identifica os animais com suas marcas (SILVA, 2009). É algo que diz respeito à identidade; outros povos indígenas também possuem suas próprias características identitárias.

Para os Kaingang, a figura masculina (do pai) é o que define a descendência, a perpetuação de seu clã. Consequentemente, um filho de kanhru, sendo homem ou mulher, será kanhru; já filhos de pai kamẽ serão kamẽ.

Para casar é necessário ser de metades ou de marcas diferentes, ou seja, kamẽ só pode casar com kanhru e vice-versa, ainda que excepcionalmente aconteçam casos em que as mesmas metades se casem. O casamento entre duas metades iguais é considerado incesto: como se fosse uma relação entre parentes, não necessariamente por serem consanguíneos, mas devido à marca com que são identificados. Nesse caso, se o casal se desentende o homem não pode procurar as lideranças para registrar queixas (pois serão punidos os dois, conforme leis internas de cada Terra Indígena), nem tampouco ter 
direito a cargos (ser policial, cabo ou membro da liderança política local), mas podendo, sim, ficar com a esposa.

Existem também casos em que não é aconselhado o casamento de uma mulher Kaingang com um homem não Kaingang, pois desse relacionamento nasceriam crianças não Kaingang, enquanto que o homem Kaingang pode se casar com a mulher não Kaingang e originar, desse casamento, filhos Kaingang. O que é muito observado ou levado em conta é que, se a mulher Kaingang casar com um homem branco (fóg ti), esta não deve permanecer dentro da Terra indígena; ela deve sair com seu esposo para uma nova morada. Já o homem Kaingang, casando com uma mulher não Kaingang (fóg fĩ), pode trazê-la para morar na Terra Indígena, acreditando-se que essa união não trará problemas. As uniões são feitas pelos Kujàs. Os kujàs são detentores dos saberes espirituais, da comunicação entre seres da natureza, do uso de ervas como tratamento, curas, além de conselheiros; cuidam da manutenção da cultura do povo Kaingang.

Numa pesquisa de campo realizada no dia 05 de março de 2014 na Terra Indígena (TI) de Nonoai, RS, em conversa com o kujà Jorge Garcia, este auxiliou um dos pesquisadores a identificar a metade clânica à qual ele pertence.

- Meu nome é Darci Kaféj Emiliano, de que marca que sou?

- Você deve se informar sobre seu "jóg", pai, se ele for kanhru os seus descendentes serão todos kanhru e se for kamẽ, seus descendentes serão todos kamẽ.

- Se meu pai não souber a sua marca, como procedo?

- Nesse caso um kujà poderá te dar ou ajudar a descobrir sua marca, podendo ser através do batizado com madeira e dando o nome desta madeira a quem for batizado [neste caso], kaféj - folha.

- Há caso em que também é notado nos traços do corpo, por exemplo, nos dedos, as unhas terem aquela parte branca, sendo grande ou pequena; isto tem fundamento?

Jorge Garcia respondeu-me que sim e perguntei se ele poderia ver as minhas unhas.

- Sim, as suas unhas são curtas e redondas. (EMILIANO, 2015) 
No mesmo momento, lá se encontrava a filha do kujà Jorge, que mostrou as unhas dela para compará-las às do pesquisador. Suas mãos e dedos são compridos; o kujà diz que ela é kamẽ; então, com dedos e unhas curtas, o pesquisador é kanhru.

As marcas são passadas de geração em geração, assim como suas histórias essas, através da oralidade.

A questão do kamẽ e do kanhru é apenas uma porta de entrada e devemos ter o cuidado para não folclorizá-la, pois se relaciona a toda uma concepção de mundo norteada pela floresta. Ao se conversar com os mais velhos, é possível ascender a um pensamento muito antigo dos Kaingang e se deparar com o saber de que a floresta é quem os ensinava. Os Kaingang são povos da floresta e, observando na floresta os movimentos dos seres visíveis e invisíveis que a habitam, aprendem os conceitos mais fundamentais da vida. Ela é a própria universidade Kaingang.

Figura 1 - Marcas de kamẽ e kanhru no artesanato

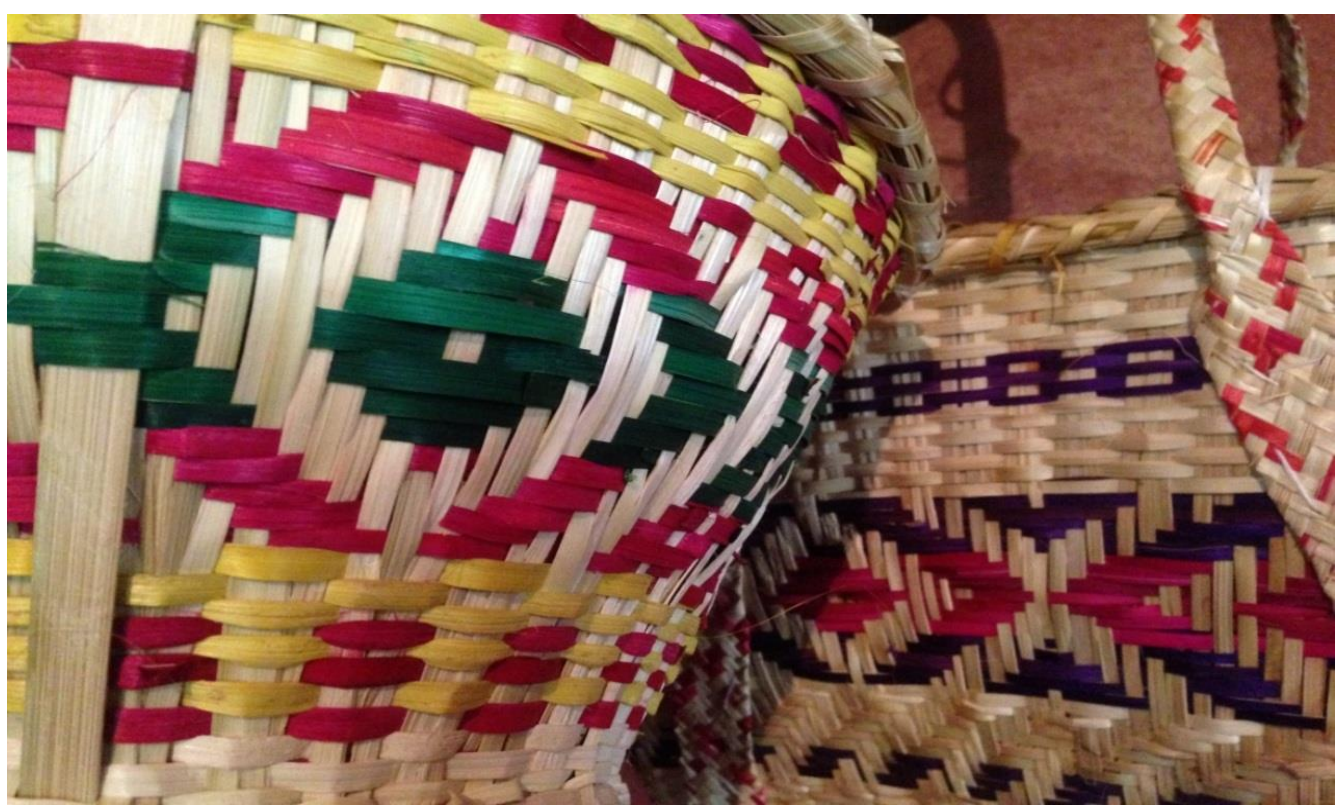

Fonte: Arquivo de Darci Emiliano, 2014 
De acordo com o professor e antropólogo Rogério Réus Gonçalves da Rosa, em banca de qualificação da dissertação de mestrado de um dos autores deste artigo, Revitalização dos saberes e práticas Kaingang sobre as plantas tradicionais como proposta de educação ambiental na Terra Indígena Ligeiro, realizada em 30 de maio de 2014, derrubar uma floresta para um Kaingang é como derrubar uma universidade ou uma igreja católica, para os brancos.

Se nós chegássemos hoje e botássemos abaixo a FURG, UFRGS, UFPEL e outras Universidades, os brancos ficariam "desmontados" - ainda mais se os proibissem de pensar da forma como aprenderam, pois foi isso que implicou para os Kaingang as derrubadas das florestas pela ação das madeireiras e, atualmente, pelo plantio da soja e do milho. Estes últimos competem diretamente com a floresta e por mais que alguns jovens Kaingang neguem estas questões, o conhecimento adquirido na floresta ainda é uma construção milenar, que não se perde em cem ou cento e cinquenta anos. A floresta ainda é o epicentro do pensamento Kaingang, então por mais que o jovem diga que é coisa do passado, o modo como ele pensa ainda está profundamente orientado por esta conexão com a floresta (ROSA, 2014).

São esses os fundamentos do pensamento Kaingang, mas, atualmente, quando se chega a algumas Terras Indígenas, os jovens indígenas dizem que esses costumes são “coisas de velho", que não existem mais e, portanto, deixando de ter interesse na causa indígena.

Em palestra proferida em novembro de 2012, em evento do Núcleo de Estudos Afrobrasileiros e Indígenas - NEABI, em Bento Gonçalves, RS, o índio José Cirilo 3 afirmou que os indígenas de seu povo ainda se alimentam do mbojapé, o pão dos guaranis (semelhante ao ẽmĩ, o pão dos Kaingang). Quando os guaranis estão vendendo artesanato no centro de Porto Alegre, lembram que naquele lugar havia árvores de frutas nativas, chamadas Aguaí, das quais os índios se alimentavam; com a colonização e a construção da cidade, os não indígenas afastaram cada vez mais os guaranis daquele local e cortaram aquelas árvores. Por meio das histórias passadas oralmente, de geração em geração, pelos guaranis, estes

\footnotetext{
${ }^{3}$ Karaí (líder) guarani Mbyá, tronco linguístico tupi, morador da Lomba do Pinheiro, em Porto Alegre, RS.
} 
retornam constantemente àquele local, na esperança de reencontrar esses frutos. Como não os encontram, entendem que o não indígena deve, de uma forma ou de outra, pagar por essa dívida com os guaranis, retribuindo com um pedaço de pão ou de alimentos; para eles, isso não é mendigar e, sim, cobrar uma dívida histórica dos brancos para com a comunidade indígena.

No mito Kaingang da origem do milho, do feijão e das morangas, apresentado na dissertação de Haverhoot (p.157, com base em Borba, 1908, p. 23), conta-se que:

\begin{abstract}
Os antepassados indígenas viviam das frutas e do mel para a sua alimentação, quando estes faltavam, a tribo passava por necessidades e fome. Um certo dia um índio velho, chamado "nhara", sentindo pena de seu povo com o sofrimento pela fome, ordenou que seus filhos e parentes fizessem um roçado com cacetes, estes atenderam o pedido. $O$ velho pede que busquem cipós grossos. Levaram o velho para ver o roçado, estando lá o velho disse ao povo que o amarrassem em seu pescoço e o puxassem pelo roçado todo e que retornassem somente três luas após para ver a lavoura, a princípio ninguém concordou, uns ficaram tristes, outros choravam, mas o velho disse que já tinha vivido o suficiente na terra e que era momento de sua partida para a morada com "NHANDERÚ" (Deus para os Guarani, ou "TOPË" Deus para os Kaingang), mas que antes deixasse algo para seu povo, logo continuou: me arrastem por toda as partes da lavoura e quando eu estiver morto, me enterrem no meio da lavoura e vão para o mato sobreviverem de frutos por três luas. Estes atenderam seu pedido e retornaram após as três luas e viram a roça coberta de milho, feijão e morangas, quando esses no ponto de colheita chamaram o povo e repartiram as sementes. Dizem que o milho é daqui e não foi trazido pelos colonizadores, ainda deram o nome de "nhara" ao milho em homenagem ao nome do índio, pelo seu sacrifício em beneficio a seu povo.
\end{abstract}

Nesse mito está presente o dualismo de Kamẽ e Kanhru, na formação da sociedade e da natureza. Esse dualismo reforça aspectos presentes no cotidiano que demonstram relações socioambientais sobre como se dá a relação natureza-humanidade.

É necessário que os antropólogos que venham a trabalhar com a questão indígena ajudem a enfrentar os desafios da preservação das florestas, pois o motivo de sua derrubada não é só vinculado ao agronegócio (para plantação de soja), mas também da 
ordem do patrimônio: colaborando com os povos indígenas para fiscalizar a aplicação das leis e estatutos, busca-se preservá-la, já que a floresta é a base das concepções de mundo, de vida e o epicentro da cultura Kaingang.

Neste contexto, entende-se que a Educação Ambiental está também caracterizada por preservar valores sociais, organização, mitologias e crenças, na coletividade de um povo.

\section{História e memórias, presente e passado}

\section{Depoimento do administrador da TI Ligeiro}

No dia 20 de novembro de 2014, durante o processo de pesquisa para a dissertação de mestrado Revitalização dos saberes e práticas Kaingang sobre as plantas tradicionais como proposta de educação ambiental na Terra Indígena Ligeiro, se obteve depoimento do administrador da FUNAI responsável pela TI Ligeiro, Lourinaldo Velozo. Conforme seu relato, chegou àquela terra indígena ainda criança, na década de 1960. Seu pai trabalhava com os índios e na época havia duas serrarias, que não eram dos índios nem do Serviço de Proteção aos Índios - SPI ${ }^{4}$, e sim dos madeireiros, os irmãos Lospel, que serravam madeiras noite e dia. Vendo aquele desmatamento de pinheiros e madeira de lei, os indígenas fizeram um movimento para tirar as serrarias do local.

\footnotetext{
${ }^{4}$ Criado em 1910, dentre as diversas funções do Serviço de Proteção aos Índios (SPI) podemos destacar: prestar assistência aos índios; civilizar os indígenas; contatar índios isolados; transformar os indígenas em trabalhadores rurais; pacificar os índios; prestar assistência educacional; prestar assistência à saúde; aldeamentos indígenas. As pessoas que atuavam nessas funções geralmente eram militares e não possuíam preparação, interesse ou identificação com a proposta do órgão. Casos de fome, doenças, genocídios e escravização eram permanentemente denunciados no início da década de 1960. Sob denúncias, o SPI foi investigado por uma Comissão Parlamentar de Inquéritos. O processo levou à demissão e suspensão de vários funcionários de todo escalão. Em 1967, em meio toda essa crise institucional e com o início da ditadura, o SPI foi extinto e substituído pela FUNAI. Fonte: $<w w w . f u n a i . g o v . b r>$.
} 
Os índios na época aprenderam a trabalhar com marcenaria e carpintaria - as famílias de Candinhos, Manoelzinhos, Cabo Vicente, Laurentino Felix, que faziam móveis, armários etc 5 .

Atualmente, os servidores da FUNAI se localizam nas cidades próximas, depois de uma saída brusca das TI, em 2009, no governo Lula. O agente da FUNAI se retirou, então, da TI e passou a atuar na Coordenação Técnica Local - CTL, que em relação à TI Ligeiro fica na cidade de Tapejara, RS. Em Ligeiro, em 2014, só havia um administrador concursado, um técnico agrícola e uma estagiária. As pessoas que tinham experiências com os índios se aposentaram e outras faleceram, havendo urgência na reposição de servidores através de concursos públicos.

\section{Depoimentos Kaingang sobre o "panelão"}

Entre os depoimentos colhidos para a pesquisa mencionada, estão os de Dona Terezinha Kasĩ Lima, de 63 anos de idade, e do Sr. Domingos Rosa, de 69 anos. No dia em que os depoimentos foram concedidos, mais uma vez o nosso pesquisador indígena chegava numa manhã de sol, após alguns dias de chuva, na residência de Dona Terezinha e do Sr. Domingos. Era sexta-feira, 30 de janeiro de 2015. A conversa aconteceu naturalmente, no idioma materno Kaingang, sempre utilizado quando se está dentro da TI Ligeiro, ou em qualquer outra TI Kaingang. Como é costume indígena tomar chimarrão, o pesquisador levou consigo um pacote de erva-mate de $1 \mathrm{~kg}$, para que pudessem chimarrear. Na conversa, o casal foi perguntado sobre o "panelão" ou "turma", expressão utilizada para designar o trabalho escravo dos parentes, há algumas décadas.

Contaram que isso aconteceu no início dos anos 1960. Na época do SPI, tentaram fazer com que os índios trabalhassem coercivamente nas lavouras, que na época eram coordenadas pelos administradores da FUNAI e lideranças políticas indígenas. Porém, os índios não usufruíam dos resultados obtidos do plantio e colheita, excetuada a alimentação.

\footnotetext{
${ }^{5}$ Falta isso para capacitar nossos indígenas; os órgãos governamentais poderiam investir nesses cursos e em pessoas que se identifiquem com questões indígenas.
} 
Participavam desses trabalhos índios a partir de nove ou dez anos de idade; formavam um grupo de 60 a 80 indivíduos. Em regime nômade, trabalhavam em lavouras da plantação à colheita, roçavam matas com auxílio de machado e foice e, posteriormente, queimavam e plantavam feijão, milho e trigo com auxílio de enxadas e paus com pontas. Não utilizavam adubação, tampouco agrotóxicos, então limpavam as roças com capina.

Figura 2 - Panelão utilizado nas lavouras

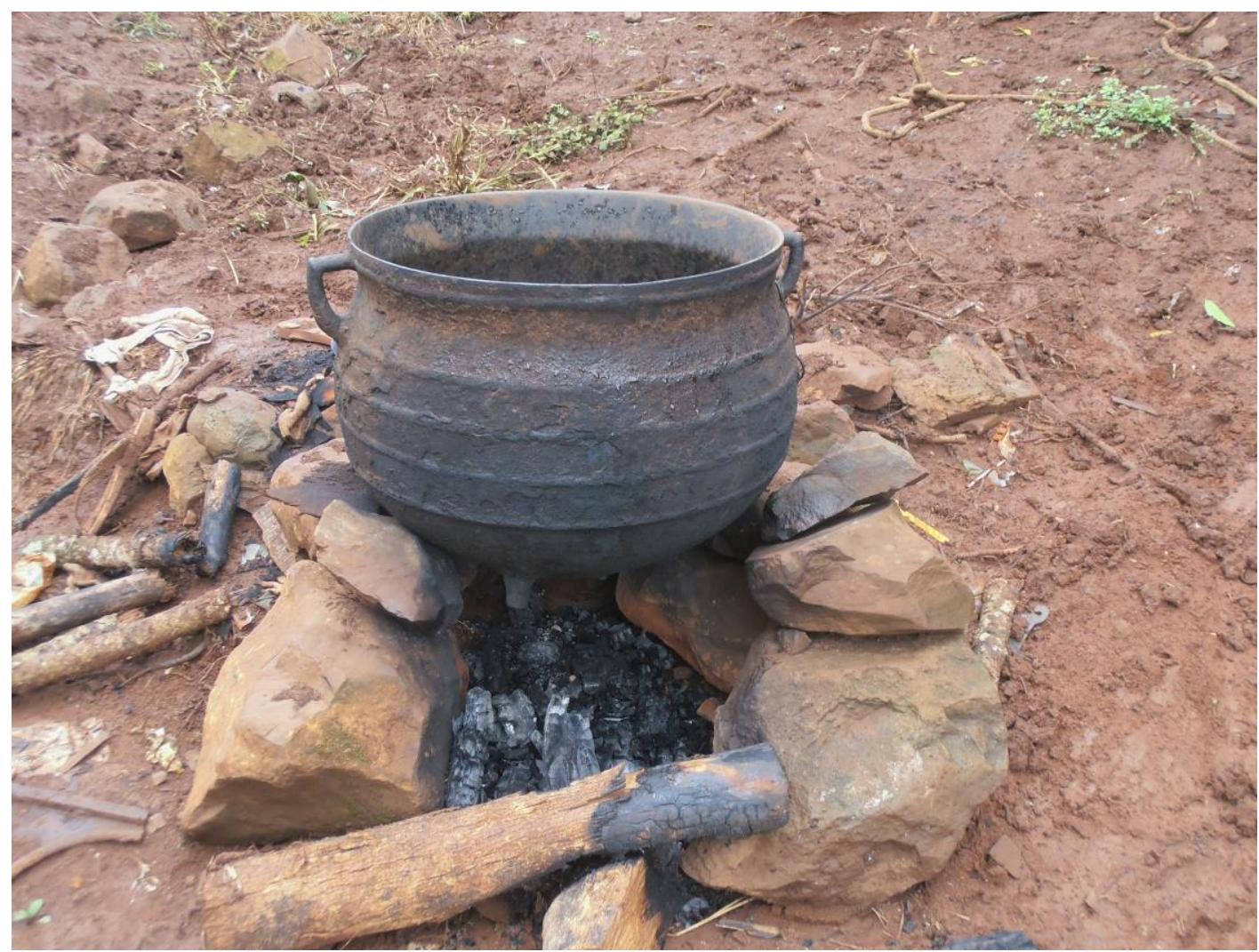

Fonte: Arquivo de Darci Emiliano, 2014

O horário de trabalho seguia das $06 \mathrm{~h}$ às $12 \mathrm{~h}$ e das $13 \mathrm{~h}$ às $17 \mathrm{~h}$ e, quando da colheita, ficavam trabalhando também durante uma parte da noite, levantavam cedo e enfrentavam filas para o café. Durante a manhã, era servida farofa de farinha de milho e café; ao meio-dia, o almoço era composto de feijão com farofa e à noite, no jantar, também feijão com farofa. A carne era somente de caça e servida uma vez por mês. As 
refeições eram feitas para aproximadamente 80 a 100 pessoas, em grandes panelas de ferro - daí surgiu a história do "panelão". As panelas de ferro ainda são utilizadas pelos Kaingang na TI Ligeiro e são de uso coletivo.

As roupas utilizadas eram de tecido de pouca qualidade, denominado "volta ao mundo" e riscado; não tinham calçados. A casa no acampamento era fabricada com guarana prẽ, vegetal usado na cobertura e nas laterais das casas, algumas delas feitas de taquara vãn.

Quem não quisesse trabalhar naquele sistema escravo era punido e castigado. Diante dessa situação, alguns índios fugiam e iam morar em outras terras indígenas ou cidades, mas eram buscados e levados de volta pelas lideranças políticas indígenas. Com os protestos de alguns índios diretamente em Brasília, esse sistema de trabalho escravo foi extinto no ano de 1970, já sob a FUNAI.

A FUNAI nasceu com a extinção do SPI, através da Lei n. 5.371, de 05 de dezembro de 1967, com finalidades como:

- Proteger e dar suporte aos índios;

- Contatar índios isolados;

- Demarcar terras;

- Promover o desenvolvimento sustentável;

- Garantir saúde e educação;

- Realizar a divulgação cultural;

- Pesquisar e reunir dados da população indígena;

- Promover e proteger direitos indígenas;

- Evitar ações de madeireiros, garimpeiros e arrendamentos das terras ${ }^{6}$.

Desde o Decreto n. 5.484, de 27 de junho de 1928, foi estabelecida a "relativa incapacidade jurídica dos índios" e afirmado o poder de tutela do SPI (posteriormente, da FUNAI). Tais dispositivos, entretanto, partiam de uma noção genérica de "índios", pois

\footnotetext{
${ }^{6}$ Fonte: <http://www.funai.gov.br>.
} 
visavam, por um lado, proteger as terras e as culturas indígenas, mas, por outro, a transferência territorial dos nativos para liberar áreas destinadas à colonização, impondo assim a profunda alteração de seus modos de vida.

Com a Constituição de 1988, os índios deixaram de ser tutelados, sendo autodeterminados; tendo, portanto, o direito de assumir o controle de sua vida, passando a ter que responder pelos seus atos perante a lei e a sociedade. O processo é recente, e ainda persistem relações instituídas de dependência sob uma grande parte da população indígena.

Em 1990, a Educação indígena passou a estar sob a coordenação dos governos estadual e municipal, restando para a FUNAI a função de assistência com benefícios sociais, auxílio-doença, auxílio-maternidade, aposentadorias, implantação de políticas públicas, demarcações de terras etc.

Em 1998, as questões específicas da saúde indígena passaram a ser de responsabilidade da FUNASA - Fundação Nacional da Saúde e, mais recentemente, do SESAI - Secretaria Especial de Saúde Indígena.

\section{Perspectivas da natureza e desafios contemporâneos}

\section{Relação harmônica com a natureza}

Historicamente, os indígenas são conhecidos como preservadores do meio em que vivem. Existe uma relação recíproca de cuidados e respeito.

Para os Kaingang, o rio é sagrado: nele, os kujà falam com o espírito das águas para que conduzam certas doenças para longe das aldeias. É também fonte de alimentos, tais como peixes. Sabe-se que, para o não indígena, a água já está sendo motivo de guerra entre nações, comercializada a preço de ouro, e mesmo assim ele acha que é uma fonte inesgotável, consequentemente não a valorizando e vindo a polui-la.

Em relação às matas, são fontes de alimentos e de ervas e plantas medicinais para cuidar da saúde física e mental do povo. Os índios vivem para manter a biodiversidade, e os Kaingang, como povos da floresta, não querem abandonar sua forma tradicional de 
sustentabilidade, utilizando essas fontes para subsistência e não com objetivo de ganância.

Dos pinheirais, os índios se alimentam de seus frutos, os pinhões, que são colhidos nos meses de março a junho e consumidos de várias formas: cozidos na água e sapecados nas próprias grimpas (folhas do pinheiro), sendo essa considerada uma de suas principais fontes de alimentação.

\section{INVERNO KAINGANG,}

Tempo do pinhão

FÁG FY é o termo, na língua kaingang, para dizer "pinhão" (lit. semente do pinheiro). Os pinheirais e seus frutos, os pinhões se confundem com a história do povo kaingang, que construiu a sua cultura à sombra deles, alimentando-se dos seus saborosos $e$ abundantes frutos (e, não menos importantes, também dos animais de caça que acorriam para alimentar-se, e engordavam de pinhões). O SPI, nas décadas de 1950 e 1960, e a FUNAI, nas décadas de 1960 a 1980 , não titubearam em saquear vorazmente os pinheirais ainda existentes em terras kaingang (como Nonoai, Guarita, Cacique Doble, Votouro, Ligeiro, Xapecó, Mangueirinha, Guarapuava, Apucaraninha etc.). Até hoje ninguém foi responsabilizado pelos crimes ambientais cometidos nas terras dos kaingang. ${ }^{7}$

\section{Meio ambiente natural}

A expressão "meio ambiente" é totalmente redundante, uma vez que as palavras “meio" e "ambiente" pretendem expressar praticamente a mesma ideia.

Ao mesmo tempo, a definição de meio ambiente é muito ampla: ele pode ser designado como a junção de todos os elementos que nos rodeiam (naturais, artificiais e culturais) e que nos propiciam uma sadia qualidade de vida, prevalecendo, aqui, a proteção à saúde e ao bem-estar da sociedade.

\footnotetext{
${ }^{7}$ Fonte: <http://www.portalkaingang.org>.
} 
Como destacado por Schonardie (2005, p. 28), conforme a norma jurídica (Lei n. 6.938/81, em seu Art. 3, inciso I), a expressão “meio ambiente” pode ser conceituada como "o conjunto de condições, leis, influências, alterações e interações de ordem física, química e biológica que permitem, abrigam e regem a vida em todas as suas formas."

Pode-se classificar o meio ambiente em natural, artificial, cultural e do trabalho (SCHONARDIE, 2005). Aqui, cabe referência especial ao meio ambiente natural, composto pelo solo, água, ar atmosférico, flora e fauna.

O meio ambiente natural, anteriormente à Constituição Federal Brasileira de 1988, era considerado um bem inesgotável. A partir dessa Constituição tal pensamento tomou outro rumo, uma vez que se trata de um bem não renovável, além de ser de uso da coletividade, conforme explicita o seu Art. 225:

Todos têm direito ao meio ambiente ecologicamente equilibrado, bem de uso comum do povo e essencial à sadia qualidade de vida, impondo-se ao Poder Público e à coletividade o dever de defendê-lo e preservá-lo para as presentes e futuras gerações. (BRASIL, 1988)

De acordo com os ensinamentos de Silva (1998), o meio ambiente natural ou físico pressupõe a “interação dos seres vivos e seu meio, onde se dá a correlação recíproca entre as espécies e as relações destas com o ambiente físico que ocupam”. Isso significa que os seres vivos devem usufruir do seu meio de forma integrada, mas sempre com vistas à sua preservação.

\section{Terras Indígenas}

De acordo com a Constituição mencionada, as Terras Indígenas são bens da União e territórios de ocupação tradicional, sendo reconhecida aos índios a posse permanente e o usufruto exclusivo das riquezas do solo, dos rios e dos lagos nelas existentes. As TIs regularizadas pelo poder público devem ser: habitadas em caráter permanente; 
importantes para suas atividades produtivas; imprescindíveis à preservação dos recursos necessários ao seu bem-estar; necessárias à sua reprodução física e cultural.

O Decreto 1775/1996, do Ministério da Justiça, estabelece que o processo de demarcação de $\mathrm{TI}$ deve ser conduzido pelo Poder Executivo, no âmbito do órgão indigenista, a Fundação Nacional do Índio - FUNAI. Esse processo é constituído por diversas fases: 1 - Estudo de identificação; 2 - Aprovação da FUNAI; 3 - Contestações; 4 Declaração dos limites da TI ; 5 - Demarcação Física; 6 - Homologação; 7 - Registro.

As lutas históricas por terras não são movimentos recentes: ocorrem desde o início do contato com os europeus, quando os portugueses invadiram as terras indígenas. Os habitantes originários foram considerados xucros, selvagens e canibais e sendo caçados como animais e não considerados como pessoas; a partir de então começa a prática do genocídio. Com a vinda dos imigrantes, nas iniciativas de colonização, foi fundamental a conivência do Estado nesse processo.

Nota-se que os aldeamentos ocorrem não somente pelo interesse do Estado, mas pela resistência do povo Kaingang; a partir de então começam os conflitos entre índios e colonizadores, o que ainda acontece nos dias de hoje. Tais conflitos são decorrentes principalmente do desmatamento. "Nós, indígenas, temos consciência quanto à fonte de vida..." que está sendo ameaçada e não é só a humana, mas também a dos animais que ali habitavam, "pois, sob a ótica indígena, em relação à natureza, a nossa prática não deve impactar com o tempo" (EMILIANO, 2015, p. 37).

Nas décadas de 1950 e 1960, o governo do estado do Rio Grande do Sul começou a distribuir, doar e vender terras para colonizadores, fazendo a reforma agrária com as terras indígenas, tornando menores as áreas ocupadas por eles. Nessa época, foi também iniciado o processo de demarcação das terras. É principalmente em relação a essas terras usadas para reforma agrária que ocorrem as lutas de retomada por parte dos Kaingang, os quais já tiveram êxito, em parte. 


\section{Transgênicos}

Dentro da TI Ligeiro e de outras Terras Indígenas do Brasil, a princípio havia sido proibida a implantação de transgênicos - organismos geneticamente modificados. Mas, em pouco tempo, foi introduzido o plantio de soja e de outros produtos transgênicos. Tal prática foi proibida pelo governo federal, pois as TIs são terras da União.

Entende-se que a introdução de plantas geneticamente modificadas no ambiente gera riscos de perda da biodiversidade, como a ameaça à população de plantas nativas. $O$ interesse econômico pelos transgênicos ocorre porque têm uma produtividade maior por área plantada e são resistentes às pragas, mas ainda faltam estudos que comprovem o que essas mudanças ocasionam para a saúde e a natureza. Isso gera um impacto muito grande, em termos de miserabilidade alimentar, na população indígena, vulnerável e dependente de cestas básicas, que são insuficientes. Além disso, e por causa da monocultura, poucas famílias conseguem, com regularidade, alcançar a produção ou o acesso ao alimento. Há necessidade de produzir alimentos com qualidade e quantidade para suprir a exigência alimentar da comunidade indígena, revitalizando a diversidade dos alimentos tradicionais: milho, feijão, brotos de abóbora, mandioca brava, morango, amendoim, batata e batata doce, caruru, erva moura, serralha, urtigão, mentruz, caraguatá do banhado.

Também devem ser levadas em conta, tanto na plantação quanto no cuidado florestal, as espécies nativas: amoreira preta, araticum, butiá, cereja, coqueiro, goiaba nativa, guabijú, guabiroba, guamirim, jabuticaba, uvaia, pinhão, pitangueira, sete capotes, vacum (EMILIANO, 2015, p. 119-122).

\section{Arrendamento e venda de áreas produtivas nas Terras Indígenas}

O que a Constituição Federal de 1988 deixa bem claro é que as TIs pertencem à União; portanto não podem ser nem vendidas, nem arrendadas ou alugadas pelos índios para não indígenas. Mas, em se tratando de arrendamento ou parcerias, permanecem 
resquícios de tais práticas em algumas terras indígenas, por mais que ambas tenham sido proibidas. Quando isso acontece e é descoberto através de denúncias, o arrendatário perde tudo o que investiu em lavouras e, como consequência, não colhe o produto plantado, arcando com esse prejuízo e ainda tendo que responder a um processo perante a Justiça. O maior prejudicado, entretanto, é o indígena, tanto do ponto de vista financeiro como da cultura e da subsistência.

Para os contrários às demarcações das TI, os casos de arrendamento são utilizados contra os próprios indígenas, mesmo que os argumentos sejam revestidos de um discurso de "preocupação e proteção". Um exemplo é o discurso do Presidente da Frente Parlamentar Agropecuária, Luis Carlos Heinze (PP-RS), que denunciou (26/04/2013) a existência de arrendamentos por parte de agricultores em Terras Indígenas, principalmente no norte do estado do Rio Grande do Sul; estimava que em torno de 35\% das terras eram arrendadas ilegalmente. ${ }^{8}$ Ele alegou que essas informações foram fornecidas por agricultores, que pagariam aluguel aos índios para plantarem. Ainda disse que a FUNAI era conivente com tais situações, que faziam com que muitos índios passassem necessidades, recebendo Bolsa-Família, sendo que alguns caciques ganhavam dinheiro. Cita, inclusive, várias reservas indígenas do estado. "Milhares de índios passando necessidades, recebendo Bolsa-Família, e meia dúzia de Caciques ganhando dinheiro", afirmou Heinze.

Os órgãos fiscalizadores são a FUNAI, a Polícia Federal e o Ministério Público Federal, os quais intensificam a fiscalização quando existem denúncias. Acreditamos que deva haver investigação das denúncias pelas instâncias responsáveis, mas também sabemos que a bancada ruralista no Congresso Nacional cria vários obstáculos para poder evitar que processos de demarcação sigam adiante.

Em algumas TIs, o que está acontecendo é a divisão de terras por famílias, como por exemplo, na TI Ligeiro Charrua, RS. Cada família recebeu em torno de 4 hectares (ha). O mais preocupante é que, posteriormente, as famílias indígenas negociam entre si a compra e venda de terras; inclusive lideranças políticas e alguns funcionários públicos

8 Fonte: <https://congressoemfoco.uol.com.br/especial/noticias/deputado-diz-que-terras-indigenas-sãoarrendadas-no-rs/>. 
com poder aquisitivo diferenciado (e por meio de abuso de poder dentro da $\mathrm{Tl}$ ) acabam adquirindo as terras dos demais e, consequentemente, se beneficiam com grandes quantidades de terras. Há denúncias acerca disso e o Ministério Público Federal vem tomando as providências cabíveis.

Há situações em que indígenas que moram dentro da aldeia e não têm terras para o seu plantio de subsistência (principalmente aqueles com menos conhecimentos, não alfabetizados, assim como aqueles que foram transferidos de uma TI para outra por motivos de conflito interno) e que, para evitar que seus familiares sofram represálias, acabam sujeitando-se a não reclamar seus direitos perante a liderança indígena.

Alguns indígenas foram contaminados pelo pensamento do não índio, se adequando ao sistema dominante capitalista que aí está: pensando em tirar proveito, se beneficiar, cercar suas dependências. Para os indígenas, isso é novidade, pois os povos originários não vivem em locais delimitados ou cercados, num sentido de propriedade privada e individual, mas sim em locais partilhados coletivamente.

Com dificuldades em conseguir financiamentos e/ou recursos para o plantio, os indígenas estão criando associações para facilitar as parcerias e tornar legal, perante a legislação, empresas que se encarregam de preparar a terra, plantar, fazer tratos culturais adequados e fazer a colheita. Com a venda do produto, pagam as despesas de produção, e com o excedente pagam, em porcentagem, para a Associação que posteriormente repassa os valores às famílias, conforme a sua área de terra. Mesmo assim, é notável a disparidade de quantidade de terras em hectares por parte de alguns índios: há os que possuem terras de 100 a 200 hectares, outros terras de 5 a 10 hectares, enquanto tantos outros nem mesmo têm terra para o plantio. Diante disso, além da maior fiscalização dos órgãos do governo federal, cabe revitalizar a solidariedade originária dos povos indígenas. 


\section{Demarcações}

A Proposta da Emenda à Constituição (PEC) 215 foi denunciada na mídia nacional e internacional pelos indígenas como mais um dos ataques a seus direitos, orquestrado pelas bancadas ruralista e evangélica do Congresso Nacional. Caso seja aprovada, transferirá do Poder Executivo para o Legislativo (Congresso Nacional) a decisão final sobre as demarcações de terras indígenas, abrindo prerrogativa para a revisão de processos já homologados.

As obras do Programa de Aceleração do Crescimento (PAC) mostraram-se também uma grande ameaça às Terras Indígenas, cabendo mencionar ainda a paralisação das demarcações das TIs no Brasil, com destaque para a região sul.

Nos governos de Lula e de Dilma Rousseff foram demarcadas menos terras do que na gestão do governo anterior e, ainda, houve mais indígenas mortos devido à luta pelas terras. Políticos ruralistas querem aprovar a suspensão das demarcações que ainda faltam e se apropriar das terras que já estão demarcadas. Sendo os deputados ruralistas donos das grandes áreas de terras, como aprovarão as próximas demarcações em favor dos indígenas?

Os povos indígenas continuam e continuarão a resistir para ter parte das terras de volta, prontos para defender a mãe natureza da ganância de exploradores, se necessário como o seu sangue.

\section{Educação}

Jovens e adultos Kaingang não sabem que direção tomar. Questionam-se: "O que estou fazendo aqui? Para onde vou? Quem sou eu?". Não tendo em quem se espelhar, sejam lideranças políticas ou autoridades locais, vivem em conflitos internos, desviando todo o foco das suas funções: apoiar, incentivar, buscar e direcionar seu povo para um caminho próspero. Não obtendo uma resposta ou mesmo um rumo a seguir, desde muito jovem o índio começa a ingerir bebidas alcoólicas. O índice de alcoolismo está em torno 
de $47 \%$ da população indígena da TI Ligeiro (dados fornecidos pelo Administrador da FUNAI - C.T.L. Coordenação Técnica Local de Tapejara, RS). Há, ainda, casos de prostituição infantil, estupros e suicídios.

O Kaingang do Ligeiro, quando necessitava, por exemplo, de carne, ia atrás da caça, da coleta de frutos etc.; ele sabia onde encontrá-los. Agora, tudo isso já não existe mais; ele sendo inserido em um sistema que lhe obriga a pensar em como poupar para o amanhã. Isso pode gerar conflito, pois, na mentalidade tradicional, o que interessa é o agora, o presente; o amanhã, dá-se um jeito de buscar suprir suas necessidades ou outro parente arrumará uma forma de compartilhar.

Há necessidade de cursos básicos de economia sobre questões financeiras e sobre como lidar com o próprio dinheiro; muitos indígenas aposentados e pensionistas não conhecem o valor do dinheiro, ficando, portanto, à mercê e dependentes de outros. Há casos em que os comerciantes, principalmente de mercados, ficam com o cartão de banco e a senha desses aposentados, fazendo todas as transações necessárias e comprometendo sempre a relação de endividamento destes para com o estabelecimento comercial; fazem, inclusive, financiamentos com esses cartões. Tais casos já foram denunciados há cerca de dez anos, quando a Polícia Federal realizou algumas prisões de comerciantes, mas ainda hoje continuam ocorrendo situações semelhantes.

Faz-se também necessária uma educação ambiental no âmbito geral, como, por exemplo, relativa à coleta e ao trato de lixo doméstico (garrafas PET, plásticos vários etc. que anteriormente não existiam nas aldeias) assim como o saneamento básico, quase totalmente inexistente na atualidade.

No ano de 2015, no processo seletivo do Instituto Federal do Rio Grande do Sul (IFRS) - Campus Sertão, participaram quatro indígenas e, destes, somente um foi aprovado para o curso de Bacharelado em Agronomia. Ainda não houve nenhum índio da TI Ligeiro com essa formação e isso só está sendo possível porque o governo federal, no ano de 2012, baixou portaria possibilitando o ingresso de indígenas e negros nos Institutos Federais de Ensino Superior (IFES) do Brasil, bem como universidades federais brasileiras, através de Sistemas de Cotas Raciais e Sociais. 
A partir do ingresso, os estudantes indígenas deveriam receber assessoramento especial para a sua permanência nos IFEs, dadas as circunstâncias e pressões que lhes são impostas pelos não indígenas. Devemos também levar em consideração a relação desses estudantes indígenas com cosmologias diferentes e outra temporalidade cultural e existencial: saem de sua rotina, na qual não há horário para dormir, comer, ficar com seus amigos, fazer as suas brincadeiras etc. e, repentinamente, são levados a cumprir horários, normas e regras rígidas que lhes são estranhas e impostas.

Devemos pacientemente dar a eles motivação para permanecerem nos estudos, conscientizando inclusive os pais, a liderança indígena e os parentes próximos, pois são familiares importantes para os indígenas. Cabe convencê-los de que, no fim da caminhada dos estudos, esta reverterá em seu benefício e de seus irmãos de etnia: o índio, quando estudar, não perderá cultura e, sim, poderá fortalecer sua identidade étnica indígena, terá noção do seu passado, valorizará, estudará a história do seu povo na Universidade para se fortalecer cada vez mais, percebendo que é importante para a história.

Alguns dirão que isso é ineficaz, mas há possibilidade de um índio passar por todas essas etapas acadêmicas e chegar a concluir cursos. Para que isso ocorra, é necessário levar a sério a política pública de inclusão e garantir o acesso e a permanência, para que os estudantes possam alcançar seus objetivos.

\section{Trabalho}

A vida dos Kaingang funciona com base na espiritualidade, que permeia aspectos culturais, dentre os quais podemos citar o artesanato. $\mathrm{O}$ uso e a presença de artesanatos fazem parte dos rituais espirituais e cerimoniais, não deixando de ser parte integrante da vida cotidiana e da cultura: armas (arcos e flechas), meios de transportar produtos e colheitas (cestos e balaios), descanso (redes) e adornos.

Nas comunidades indígenas uma das formas de gerar recursos econômicos para a subsistência é a produção de artesanato - balaios, cestos, flechas, cocares, filtros dos 
sonhos $^{9}$, trançados em canetas, braceletes etc. O artesanato pode ser comercializado na Tl e também nas cidades próximas e distantes da aldeia.

Há uma divisão sexual de trabalho na fabricação dessas peças. Algumas são feitas pelos homens - como cestos, cabos e flechas -, pois geralmente requerem, além de destreza, força; também há uso de equipamentos pesados na coleta da matéria-prima. Geralmente, os artesanatos fabricados pelas mulheres são balaios, cestas, trançados em canetas, filtros dos sonhos e braceletes. Mas nada impede que essa divisão de trabalho seja alterada ou que o trabalho de confecção desses materiais seja compartilhado.

A coleta das matérias-primas, especialmente a taquara, obedece a uma época específica, no período da lua nova, quando é mais fácil o seu manuseio. Caso, por exemplo, nesta época não seja coletada a taquara (que é a mais utilizada), corre-se o risco de que ela seja extinta e/ou não se regenere com facilidade. Quanto à coleta do cipó, existe uma época que também deve ser respeitada - a primavera -, devido à maior facilidade de manuseio. Do cipó mrũr são feitas várias formas e formatos de artesanatos: bandejas, casinhas, bolinhas, ninhos, sinos de natal, pequenos animais etc.

Na coleta da taquara é necessário cortar mais ou menos quinze centímetros da terra, logo abaixo do nó da taquara, deixando o formato de um cone e possibilitando o depósito de água das chuvas, o que facilita a brotação.

Em conversa com a índia Olinda Caetano Nunes (EMILIANO, 2015), ela explicou que houve época em que os índios Kaingang se baseavam na taquara vãn para contar o tempo, conforme o ciclo de vida da taquara: quando esta cresce naturalmente, se regenerando a cada corte aproximadamente após trinta anos, floresce, frutifica e acaba secando. Daí surge o dito popular "quanta taquara seca você tem". Então, cada taquara seca é de trinta em trinta anos, servindo também como ideia de calendário na visão desse povo; na crença Kaingang significa também três anos de seca e miséria.

\footnotetext{
${ }^{9}$ Filtro dos sonhos: amuleto que teria o poder de purificar as energias e separar os sonhos bons dos ruins, trazer sabedoria e sorte para quem o possui. Fonte: <https:// www.tuacasa.com.br>.
} 
Figura 3 - Artesanato indígena - taquara - Marina Ferreira

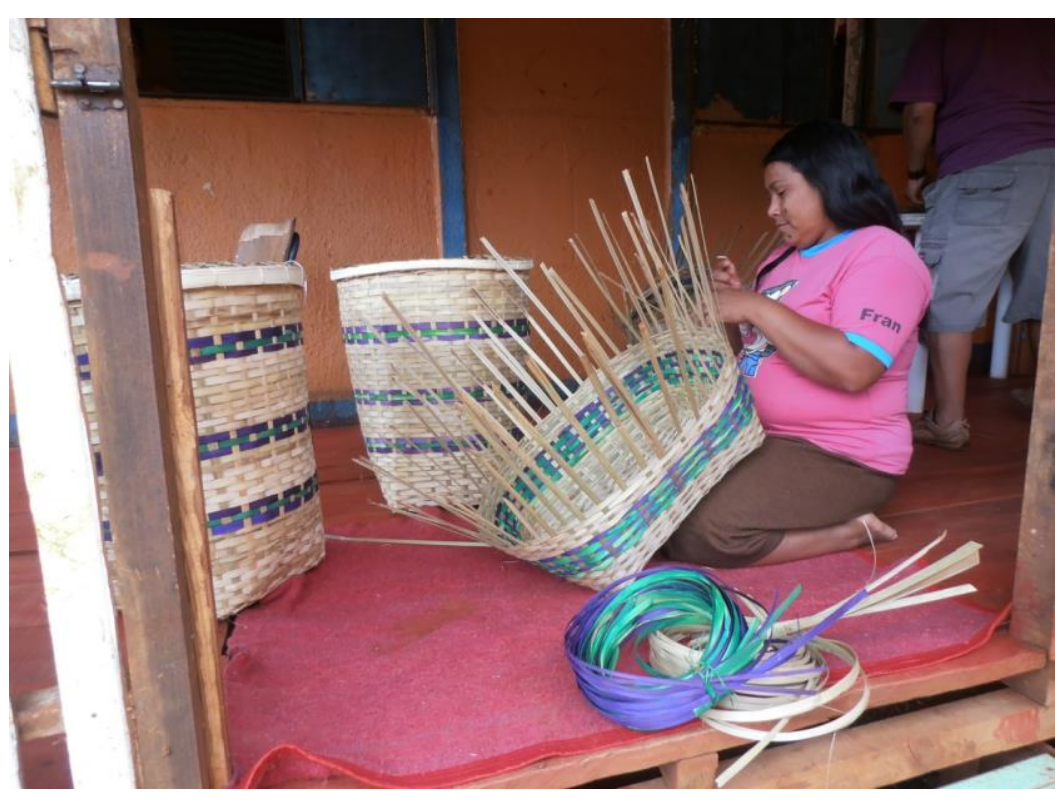

Fonte: Arquivo de Darci Emiliano, 2014

A matéria-prima está escassa, tanto que os índios compram taquara em outros locais (terras dos brancos). Nesse sentido, também se faz necessária a revitalização da taquara.

Geralmente, quem pratica a confecção do artesanato são os indígenas que não exercem outra profissão, por não possuírem instrução acadêmica ou emprego fixo; eles têm no artesanato uma forma de sobrevivência. A negociação ocorre através de troca ou venda, ainda que de forma exploratória por parte daqueles que compram as artes; caso não sejam vendidas todas as peças de artesanato, para não trazê-las de volta à casa trocam-nas por galinha, ovos, frutas e até por bebidas alcoólicas.

O preço que os índios pedem pela venda de seus produtos é baixo, por mais que seja árduo o trabalho de produção. A coleta e a confecção são difíceis. Sendo conscientizado, o comprador observará o valor histórico, a arte e a identidade impregnada neste artesanato. Mas ainda há concorrência com materiais feitos de plástico. 
Para que se tenha uma ideia da complexidade do processo de produção, cabe narrar alguns de seus passos:

- Em um belo dia pela manhã, se encontra um grupo de índios, composto de homens, mulheres e crianças, para se deslocar até um lugar distante da aldeia e coletar matérias-primas (taquara, cipó, taquaruçu, madeira, fibras, palhas, sementes e penas); $;^{10}$

- Pelo fato de o lugar ser distante, uma das mulheres fica encarregada de preparar a alimentação, no local da coleta, enquanto os outros realizam o trabalho braçal;

- Algumas ferramentas utilizadas nesta tarefa são a foice, a faca e o facão;

- É necessário cuidado, pois são conhecidos casos de acidentes com animais peçonhentos, tais como cobras, escorpiões e aranhas, assim como os causados pelos próprios espinhos da taquara;

- No retorno às suas casas, geralmente ao anoitecer, já cansados por terem transportado a matéria-prima, deixam a tarefa de raspar com a faca, tirar a casca e destalar as taquaras para a manhã seguinte;

- A taquara destalada com tintas é então cozida para destacar e dar contraste no material artesanal, além de identificar as duas metades, kamẽ e kanhru, a identidade étnica do grupo. Quando se trata de um artesanato rústico, como no caso do cesto para transportar colheitas, não é necessária pintura, nem raspagem da taquara.

\footnotetext{
${ }^{10}$ Dentre a enorme diversidade de culturas indígenas, cada povo tem seu universo de concepção e de uso de matérias-primas (o Guarani esculpe animais na madeira, diferentemente do Kaingang).
} 
Figura 4 - Comercialização de artesanato indígena

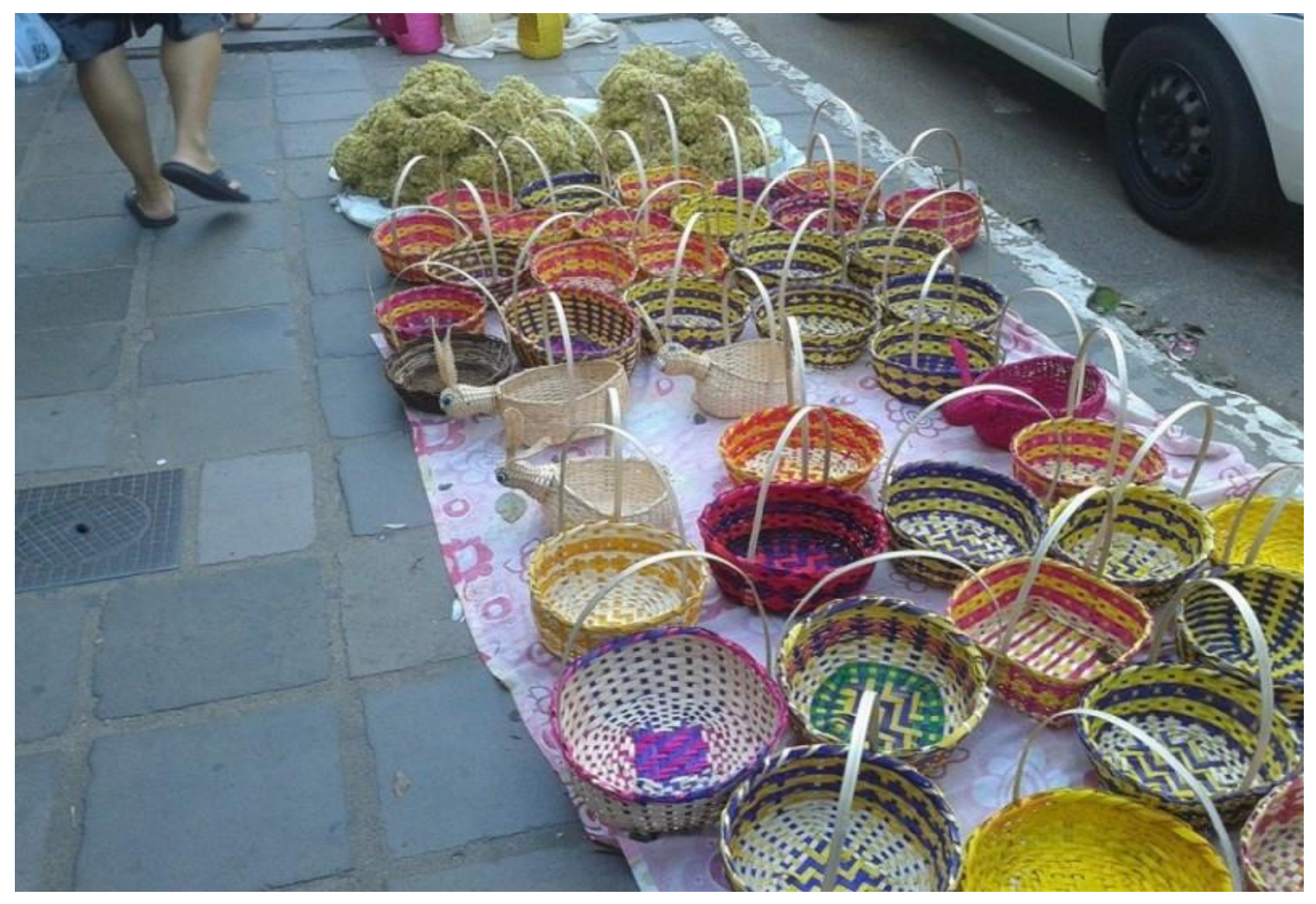

Fonte: <www.radiotapejara.com.br>, 2015 .

A produção e a comercialização do artesanato são feitas durante o ano todo, mas há épocas em que se tornam mais intensas, como, por exemplo, nas férias escolares de dezembro a fevereiro e na Páscoa, com mais intensidade nas cidades grandes e nas do litoral.

As mulheres, trabalhando com seus artesanatos, são pouco valorizadas; não têm apoio das lideranças políticas, que estão mais preocupadas com a agricultura, com o plantio de soja, sinônimos de dinheiro.

Um dos problemas enfrentados pelos artesãos indígenas ainda é a discriminação, preconceito e falta de local adequado para permanecer enquanto comercializam seu artesanato. Porém, já existem várias cidades que proporcionam esses espaços para estada, como, por exemplo, no Rio Grande do Sul, as cidades de Santa Maria, Rio Grande e Cruz Alta e, em Santa Catarina, Balneário Camboriú. 
Os índios estão sendo pressionados pela sociedade branca do comerciante, das cooperativas, dos vendedores de insumos e cereais. Sua situação não é fácil; isso ocorre mais intensamente há cerca de quinze anos, quando começou o processo da monocultura, nas TIs. O indígena vê as plantações nos limites da terra, que são as do branco, e pensa: “Por que não posso eu também?”. Fora isso, ainda há o preconceito do latifundiário: "Por que índio quer terras?”. Se não plantam, os índios são taxados de vadios, bêbados etc. Para que esse indígena comece a plantar de forma semelhante ao agricultor não indígena, são necessários cursos de curta duração ligados à questão de terras e ainda um financiamento por parte de bancos e/ou uma política específica de agricultura autossustentável.

No Rio Grande do Sul, há também opções de serviços ou trabalho (trabalho braçal, por exemplo) em empresas como Agrodanieli, no município de Tapejara; Perdigão, no município de Marau; Aurora, em Erechim. Essas três empresas atuam no ramo do abate de frango de corte. Além delas, há épocas de colheitas de maçã nas cidades de Vacaria e de Lagoa Vermelha. Para realizar o deslocamento até os abatedouros, existem meios de transportes específicos, diariamente, como ônibus; já para a colheita de maçã, os trabalhadores índios permanecem nos locais por semanas ou até por um mês, para só então retornarem à terra de origem, reverem seus familiares e, na sequência, retornarem ao trabalho de colheitas.

\section{Organização social das aldeias, liderança e gestão: a função do Cacique}

Existe uma organização social dentro de cada TI, assim como na sociedade em geral. Nesta organização, uma das autoridades mais importantes é o Cacique, que representa os membros da TI e atua: na mediação de conflitos, em busca de uma solução ou alternativa; na luta pelo bem de seu povo; na organização de festas e reuniões; na recepção a visitantes; no incentivo à preservação da cultura de seu povo; no cuidado e zelo pelas normas e regras internas.

A escolha do Cacique é feita por indígenas acima de 16 anos de idade. Cada candidato é representado por sementes (milho, feijão, soja) e o candidato que fizer maior 
número de votos (= sementes) é considerado eleito. A eleição ocorre de quatro em quatro anos em algumas TIs e, em outras, é vitalícia.

Problemas que o Cacique enfrenta e que muitas vezes o impedem de cumprir com suas obrigações:

1. O risco de vida que corre, pois sabe que está saindo da TI na busca de recursos, mas não sabe se voltará. Vários líderes foram e ainda são mortos, tanto devido ao processo de discriminação e preconceito social ser acirrado, como principalmente pelas tentativas de retomadas de terras tradicionalmente ocupadas pelos ancestrais. Porém, todos esses processos servem de fortalecimento para as lutas.

2. A complexidade da tarefa de transmitir a experiência de suas funções, doutrinar índios novos de idade para aprender a ser Cacique, para que não se perca a continuidade de luta pelos direitos do nosso povo.

3. As dificuldades financeiras em se deslocar para cidades e estados na busca de recursos para a saúde, educação, moradias, demarcações etc.

4. O desafio de usufruir da terra em benefício de todos na TI, mas sempre dando continuidade à autossustentabilidade, pensando em preservar para nossos descendentes e não sucumbir à ganância (lucros).

Uma possibilidade de solução ao menos parcial desses problemas seria o governo federal assalariar os caciques, pois, dado o trabalho que desenvolvem em prol das comunidades, quase não sobra tempo para seus afazeres nas TIs. Isso evitaria atos ilegais dos caciques com parcerias, arrendamentos e outros contratos. 


\section{Considerações finais}

Entre os Kaingang, o abandono e a falta de valorização de saberes e práticas relacionadas com a educação ambiental se concretizam pelas pressões da sociedade branca, com o desejo de alguns indígenas de se "modernizarem" e serem aceitos pela mesma, e pela ausência de orientação de educadores ambientais. As iniciativas de revitalização são possíveis e necessárias: o uso de plantas e alimentos tradicionais está relacionado com atividades que precisam ser vivenciadas primordialmente na escola, na relação com os kujà tradicionais, no desenvolvimento de projetos específicos e na motivação permanente para a responsabilidade ambiental, preservando a cultura e os costumes Kaingang que ainda são preciosos, especialmente na promoção da saúde da comunidade.

Esse entendimento revela a importância do tema, pois, de maneira geral, o desinteresse dos não índios e de alguns indígenas pela manutenção das tradições, da história, do idioma, da cultura e do conhecimento indígenas, é agravado pela morte dos anciões e dos kujàs, portadores desses saberes ancestrais, e pelas violências sofridas pelas comunidades indígenas. Isso contribui para aproximar os indígenas, na conjuntura atual, da adoção da agricultura transgênica de grãos, em grande escala, com o uso de agrotóxicos, consequentemente poluindo a natureza e os recursos naturais. Situação que remete à importância da sustentabilidade, quando se reflete sobre esta ter, como critério, a não interferência humana além dos limites de capacidade da natureza, para que possa se restituir em sua composição original.

\section{Referências}

BORBA, Telêmaco. Actualidade indígena (Paraná, Brazil). Curitiba: Impressora Paranaense, 1908.

BRASIL. Constituição (1988). Constituição da República Federativa do Brasil: promulgada em 05 de outubro de 1988. São Paulo: Saraiva, 1988. 
BRASIL. Decreto (1996). Decreto n. 1775/1996: dispõe sobre o procedimento administrativo de demarcação das terras indígenas e dá outras providências. Disponível em: <http://www.planalto.gov.br/ccivil_03/decreto/d1775.htm>. Acesso em 13/05/2017.

BRASIL. Lei (1928). Decreto n. 5.484/1928: regula a situação dos índios nascidos no território nacional. Disponível em: < https://www2.camara.leg.br/legin/fed/decret/19201929/decreto-5484-27-junho-1928-562434-norma-pl.html>. Acesso em 13/05/2017.

BRASIL. Lei (1981). Lei n. 6.938/1981: dispõe sobre a Política Nacional do Meio Ambiente. Disponível em: < http://www.planalto.gov.br/ccivil_03/leis/L6938.htm >. Acesso em 13/05/2017.

DEPUTADO diz que terras indígenas são arrendadas no RS. Disponível em: $<$ https://congressoemfoco.uol.com.br/especial/noticias/deputado-diz-que-terrasindigenas-são-arrendadas-no-rs/>. Acesso em 13/05/2017.

EMILIANO, Darci. Revitalização dos saberes e práticas Kaingang sobre as plantas tradicionais como proposta de educação ambiental na Terra Indígena Ligeiro. Rio Grande, 2015. Dissertação (Mestrado em Educação Ambiental). Universidade Federal do Rio Grande.

HAVERROTH, Moacir. Kaingang - um estudo etnobotânico. Florianópolis, 1997. Dissertação (Mestrado Antropologia Social) - Universidade Federal de Santa Catarina, Programa de Pós-Graduação em Antropologia Social.

JAHN, Lívia Petry; TETTEMANZY, Ana Lúcia; FREITAS, Ana Elisa de Castro. O papel do mito nas narrativas orais dos kaingang na bacia do lago Guaíba. Porto Alegre, Organon, (UFRGS), v. 20, p. 159-171, 2007.

KAINGÁNG, S. Fakój (Org.). Ẽg Rá: nossas marcas. 1. ed. São Paulo: DM Projetos Especiais, 2013.

ROSA, Rogério Réus Gonçalves da. Os kujà são diferentes: um estudo etnológico do complexo xamânico dos kaingang da terra indígena Votouro. Porto Alegre, 2005. Tese (Doutorado em Antropologia Social) - Programa de Pós Graduação em Antropologia Social, Universidade Federal do Rio Grande do Sul.

ROSA, Rogério Réus Gonçalves da. Parecer apresentado na qualificação da dissertação Revitalização dos saberes e práticas Kaingang sobre as plantas tradicionais como proposta de educação ambiental na Terra Indígena Ligeiro, de Darci Emiliano, na condição de integrante da banca avaliadora. Arquivo do PPGEA, FURG, Rio Grande, 2014. 
SCHONARDIE, Elenise Felzke. Dano ambiental a omissão dos agentes públicos. 2. ed. Passo Fundo: UPF, 2005.

SILVA, José Afonso da. Direito Ambiental Constitucional. 2. ed. São Paulo: Ed. Malheiros: 1998.

SILVA, Luis Freitas da. Kanhgág ag venh kógan kar ag vengrén: pintura e dança kaingang. Santo Ángelo, RS: Ediuri, 2009.

Sítio eletrônico da FUNAl: <www.funai.gov.br>. Acesso em 13/05/2017.

Sítio eletrônico da Rádio Tapejara: <www.radiotapejara.com.br>. Acesso em 12/02/2015.

Sítio eletrônico Portal Kaingang: <http://www.portalkaingang.org>. Acesso em 13/05/2017.

Sítio eletrônico Tua Casa: <https:// www.tuacasa.com.br>. Acesso em 13/05/2017.

Recebido em: 21/11/2017 Aprovado em: 28/07/2018

Universidade do Estado de Santa Catarina - UDESC Centro de Ciências Humanas e da Educação - FAED Revista PerCursos Volume 19 - Número 41 - Ano 2018 revistapercursos@gmail.com 